\title{
Seasonal changes in hydraulic flow conditions in overgrown lowland river
}

\author{
Krzysztof Wolski ${ }^{1, *}$ \\ ${ }^{1}$ Wroclaw University of Environmental and Life Sciences, The Faculty of Environmental Engineering \\ and Geodesy, Institute of Environmental Engineering, ul. Norwida 25, 50-375 Wroclaw, Poland
}

\begin{abstract}
The paper presents the results of numerical research on the impact of seasonal changes in vegetation on the hydraulic conditions prevailing in the bed of overgrowing lowland river on the example of Ślęza River (Poland). Hydrological characterization of the analyzed section of the river was made on the basis of data from the years 2006-2017 from the Ślęza water gauge. Based on them, the growing season and characteristic flows for modelling were determined. A two-dimensional hydrodynamic model (2HD) was built in two scenarios corresponding to the beginning and the end of the vegetation period for an about $50 \mathrm{~m}$ long section of the river. The bathymetric data of the bed and the plant distribution were measured in the field for both scenarios. The models were calibrated using a coefficient of roughness based on the velocities and surface elevations measured directly in the field. Various characteristic flows were then tested on calibrated and verified models for both scenarios. Changes in hydraulic conditions in both scenarios were compared by means of velocities and shear stress occurring in the riverbed. The obtained results indicate a significant impact of plants on the hydraulic conditions in the riverbed. The existence of plants causes the accumulation of backwater and change of local velocity distributions while maintaining medium and maximum velocities in the riverbed.
\end{abstract}

\section{Introduction}

Studies on the impact of aquatic vegetation on the flow conditions in watercourses are extremely complex. It is influenced by the amount of possibility of interactions between plants, hydrological and fluvial conditions as well as morphology of the riverbed [1,2]. One of the key variables is the spatial and temporal complexity of the existing vegetation. The occurring systems of plants are characterized by high species diversity, heterogeneity of occurrence and density, and - what is important for this work - in seasonal variability [3]. Seasonal variability of vegetation does not occur equally in the whole world due to the climatic conditions. It is most visible in temperate zones with distinct seasons of hot and cold year, where the temperature drops below the border to favourable vegetation conditions (depending on plants, $5-15^{\circ} \mathrm{C}$ ). Together with the distinct vegetative and non-vegetative season, the resistance induced by vegetation is significantly different due to the morphological and biomechanical characteristics of plants $[4,5]$.

\footnotetext{
* Corresponding author: krzysztof.wolski@upwr.edu.pl
} 
Differences in coefficient of roughness occurring in particular seasons of the year were indicated in many works [6-8]. In addition to identifying the roughness itself, many researchers have been comprehensively approaching the changes taking place in the riverbed, characterizing seasonal changes in hydraulic conditions occurring in the channel [9-11].

Marcinkowski et al. [12] also prove a significant effect of vegetation phases on the conditions prevailing in the anastomosing river system on the example of Narew River. They indicate that the roughness coefficients differ between the seasons (higher values in the growing season) and that there are significant differences in the distribution of water flow in the multichannel anastomosing rivers.

The vegetative phases of plants and their influence on flow conditions were also compared for the Polish conditions Walczak et al. [13]. They showed a large impact of plant vegetation phases on flow resistance and water velocity in the riverbed. They noticed that the greater convergence of the Manning's roughness coefficients $n$ (MRCn) accepted from the tables [14] can be observed in the growing season than in the non-vegetative period.

Although in many of the above mentioned works the idea of a parameter correcting the coarseness coefficient appeared depending on the vegetative phase of plants (or the seasons), in engineering practice, where the determination of MRCn is an important tool in hydraulic modelling, such solutions are not used.

Understanding the impact of plants on hydraulic and morphological conditions in the riverbed is necessary in the case of ecological river regulation (restoration of rivers) and NBS (nature-based solutions), where specifically selected plants in terms of species and density can perform specific functions such as flow deflectors $[15,16]$.

In this study, the MRCn was spatially determined on the basis of field measurements on two dates (at the beginning and end of the growing season). A two-dimensional hydrodynamic model was built, taking into account the natural conditions of the riverbed (shaping the bed and specific MRCn). Based on calibrated the MRCn of the model, the hydraulic conditions prevailing in the riverbed for different scenarios at the beginning and end of the vegetation period were compared for different flows.

\section{Study area}

The research was conducted for the Ślęza River around its 12.3 kilometre. The river basin for the analysed sections has an area of about $900 \mathrm{~km}^{2}$. The modelled section of the Ślęza River is located in the geographical location $16^{\circ} 58^{\prime} 36^{\prime \prime}$ East longitude and $51^{\circ} 04^{\prime} 53$ "North latitude. The Ślęza River is a left-bank tributary of the Odra River. Its length is about $85.1 \mathrm{~km}$, and the catchment area equals ca. $975 \mathrm{~km}^{2}$. The location of the surveyed segment of the river is presented in Fig. 1.

\section{Hydrological data}

Based on average daily data from the years 2006-2017 for the Ślęza station made available by the Institute of Meteorology and Water Management - National Research Institute, the hydrological characteristics of the section under investigation were performed. The Ślęza gauge station is located approx. $5 \mathrm{~km}$ above the analysed section of the watercourse (Fig. 1). The station has been operating since 2006, flows are measured constantly, while the water temperature was measured in years 2006-2015. Figure 2 shows measured mean daily water temperatures and average daily flows in the indicated multi-year period. 


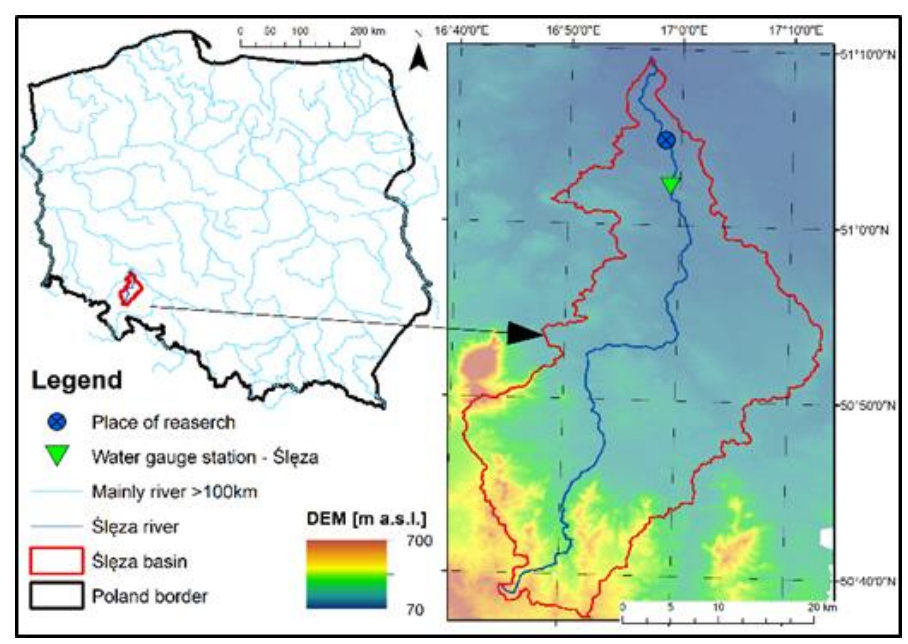

Fig. 1. Area of study - place of research on the Ślęza Basin against DEM (right) and in reference to Poland (left).

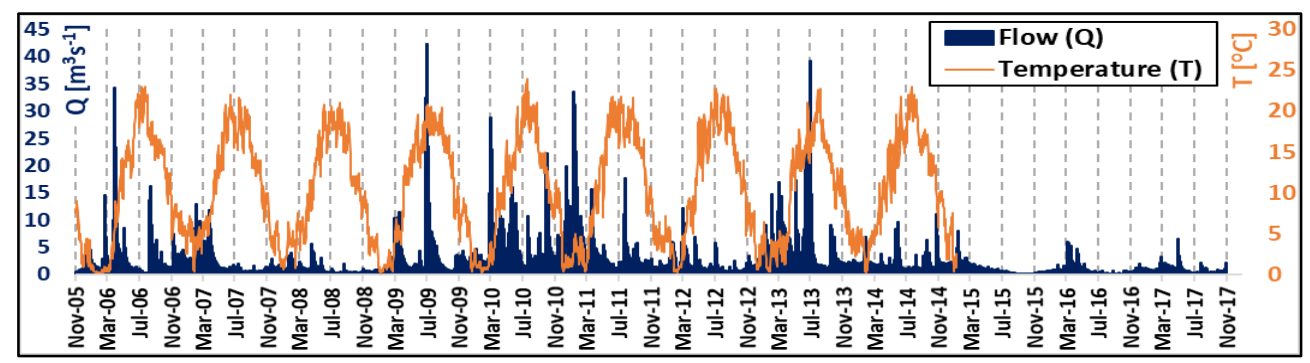

Fig. 2. The course of the daily water temperature and daily flows in the years 2006-2017 on the Ślęza water gauge (Ślęza River).

Water temperatures indicate a characteristic sinusoidal course closely related to the seasons of the year. The characteristics of water temperatures in individual months are shown in table 1. On its basis, the duration of the vegetation season for plants has been determined. It was assumed that the vegetation season is valid in months when the average water temperature is greater than 10 degrees Celsius, from April to October. The calculated monthly averages and the median of water temperatures in each month are similar, which indicates the normal distribution of the data sets. Characteristics of flows occurring in particular months were made together with the division into the vegetation season and the non-vegetation season. The results are presented in table 1.

There is a noticeable difference in the size of flows in the vegetation and non-vegetation season (mean flow in vegetative period is more than $30 \%$ smaller than mean flow in whole year). The calculated values of average flow in particular months are in each case greater than the median of flows, which indicates the deviation of results from the normal distribution and that single occurrences of larger flows occur relatively rarely, but affect the determined average flow.

For the verification purposes, histograms of the frequency of occurrence of flows for the vegetation season and comparative for the whole year were made. It was shown that low flows (below $1.5 \mathrm{~m}^{3} \mathrm{~s}^{-1}$ ) occur in the vegetation season in $60 \%$ of the time, while $49 \%$ in the entire year. This confirms that the longest flows lasting in the growing season are low flows. Therefore six flow values were adopted for comparative analyses in the models: $Q_{1}=0.5$ $\mathrm{m}^{3} \mathrm{~s}^{-1}, Q_{2}=1.0 \mathrm{~m}^{3} \mathrm{~s}^{-1}, Q_{3}=1.5 \mathrm{~m}^{3} \mathrm{~s}^{-1}, Q_{4}=2.0 \mathrm{~m}^{3} \mathrm{~s}^{-1}, Q_{5}=3.0 \mathrm{~m}^{3} \mathrm{~s}^{-1}$ and $Q_{6}=5.0 \mathrm{~m}^{3} \mathrm{~s}^{-1}$. 
Table 1. The minimum, maximum, average and median values of monthly and seasonal flow and water temperatures on the Ślęza water gauge (Ślęza River) in the years 2006-2017.

\begin{tabular}{|c|c|c|c|c|c|c|c|c|}
\hline & \multicolumn{4}{|c|}{ Temperature $\boldsymbol{T}^{\circ} \mathrm{C}$} & \multicolumn{4}{c|}{ Flow $\boldsymbol{Q}, \mathbf{m}^{\mathbf{3}} \mathbf{s}^{-\mathbf{1}}$} \\
\hline Month & $\min$ & $\mathbf{m a x}$ & mean & median & $\min$ & $\max$ & mean & median \\
\hline January & 0.1 & 7.2 & 2.4 & 1.8 & 0.5 & 33.6 & 3.5 & 2.3 \\
\hline February & 0.2 & 7.6 & 2.4 & 2.3 & 0.7 & 26.1 & 3.5 & 2.3 \\
\hline March & 0.4 & 11.2 & 5.0 & 5.0 & 0.9 & 34.3 & 4.9 & 3.7 \\
\hline April & 3.0 & 17.2 & 10.4 & 10.4 & 0.8 & 18.0 & 3.0 & 2.2 \\
\hline May & 7.0 & 20.8 & 14.9 & 14.6 & 0.6 & 17.3 & 2.6 & 1.4 \\
\hline June & 11.8 & 22.2 & 17.6 & 17.8 & 0.2 & 42.4 & 2.7 & 1.0 \\
\hline July & 15.0 & 24.0 & 19.3 & 19.2 & 0.2 & 37.5 & 2.2 & 0.9 \\
\hline August & 14.4 & 22.7 & 18.3 & 18.6 & 0.1 & 16.2 & 1.5 & 0.9 \\
\hline September & 10.4 & 19 & 14.9 & 15.0 & 0.1 & 22.2 & 1.7 & 0.9 \\
\hline October & 4.8 & 16.6 & 10.7 & 10.8 & 0.1 & 20.4 & 1.7 & 1.0 \\
\hline November & 1.0 & 11.6 & 6.8 & 7.2 & 0.2 & 7.5 & 1.9 & 1.6 \\
\hline December & 0.4 & 7.8 & 3.4 & 3.4 & 0.4 & 19.9 & 2.4 & 1.8 \\
\hline Years 2006-2015(CP) & $\mathbf{0 . 1}$ & $\mathbf{2 4 . 0}$ & $\mathbf{1 0 . 4}$ & $\mathbf{1 0 . 4}$ & $\mathbf{0 . 1}$ & $\mathbf{4 2 . 4}$ & $\mathbf{2 . 6}$ & $\mathbf{1 . 6}$ \\
\hline Vegetative period (VP) & & & & & $\mathbf{0 . 1}$ & $\mathbf{4 2 . 4}$ & $\mathbf{2 . 2}$ & $\mathbf{1 . 2}$ \\
\hline Non-vegetative period (NP) & & & & & $\mathbf{0 . 2}$ & $\mathbf{3 4 . 3}$ & $\mathbf{3 . 2}$ & $\mathbf{2 . 1}$ \\
\hline
\end{tabular}

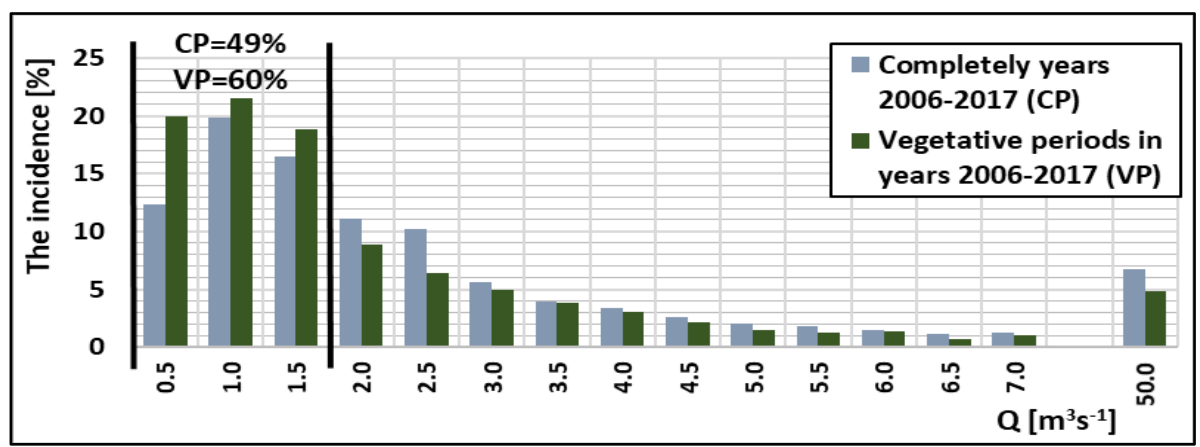

Fig. 3. Histogram of the incidence of flows during the vegetation season and throughout the year on the Ślęza water gauge (Ślęza River) in the years 2006-2018.

\section{Methods}

\subsection{Field measurements}

Field measurements were carried out throughout 2018. Figure 4 shows what the research stand looked like in four phases of vegetation in 2018. It can be noticed a very large variation in the number of plants in the riverbed in individual months. The main measurement work was carried out in two series on April 14-19 in the initial vegetation season and on October 11-14 in the final vegetation season. In 2018, for almost the entire summer during the maximum vegetation there were very low flows, which in combination with the developed vegetation did not allow for stable and reliable measurements.

As part of the measurements, the bathymetry of the bed was mapped in the $1 \mathrm{~m} \mathrm{x} 1 \mathrm{~m}$ grid (Fig. 5) as well as the development and density of vegetation (on a scale from 1-3). At the same time, the water velocities in the hydrometric divisions were measured using the Mini Current Meter (SEBA M1) and in the cross-sections profiles using an acoustic Doppler 
current profiler (StreamPro ADCP). The measured water flow rates were then used to calibrate the numerical model.

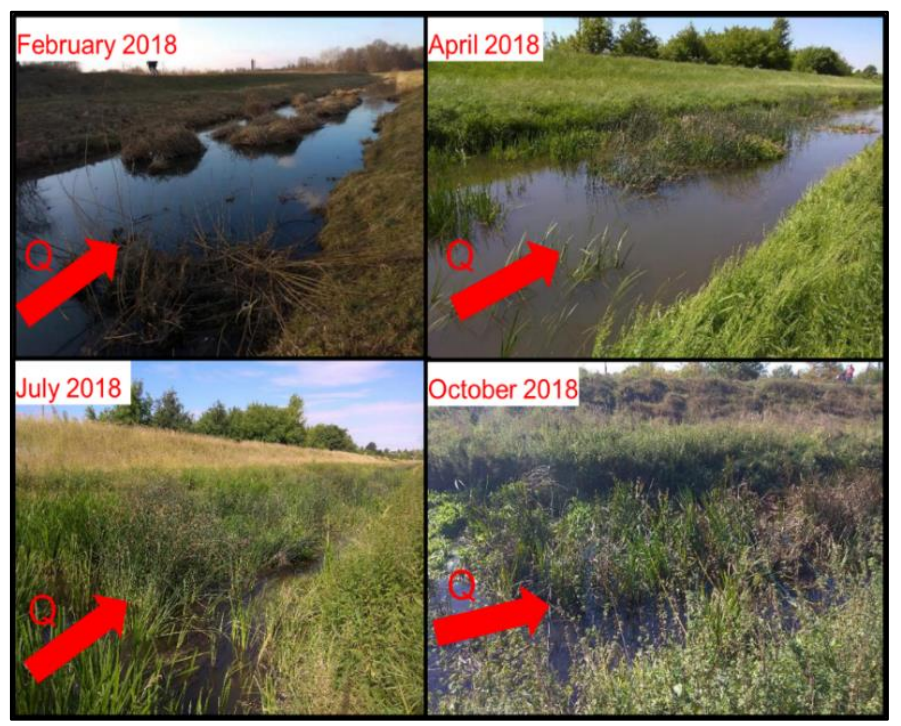

Fig. 4. Measuring station in 2018 (dates in the drawing).

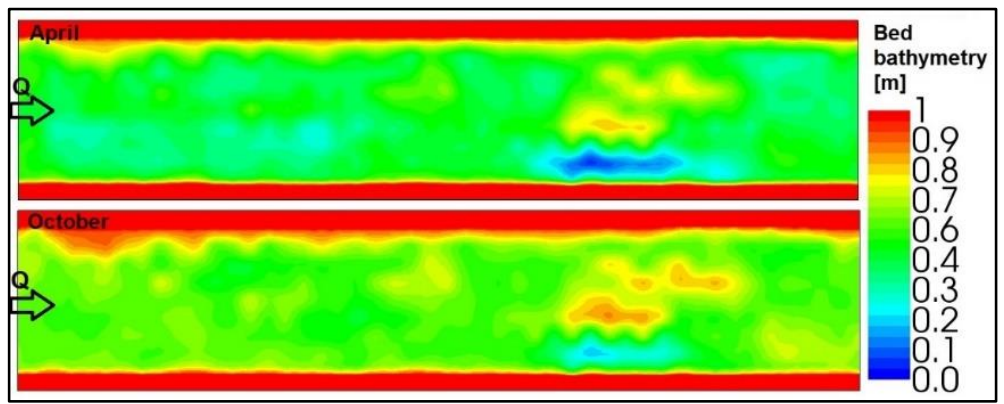

Fig. 5. Distribution of the bed bathymetry in April (scenario 1) and in October (scenario 2).

During measurements in the riverbed there were characteristic groups of species among which typical macrophytes can be distinguished: helophytes (rush - Phragmites australis, Glyceria maxima, Scirpus lacustris and Sparganium erectum), elodeids (submerged - Elodea canadensis and Myriophyllum L.) and aquatic perennials (growing on shallowing - Alisma plantago-aquatica L. and Rumex hydrolapathum Huds.). The spring season was dominated by helophytes - withered clusters of last year shoots and young sprouts growing in them, and to a lesser extent, elodeids. In the autumn, the number and density of helophytes have increased significantly, some of which stems are already in a dry form. The intense growth of helophytes has stopped the elodeids, which occur only in few trims, but occupy less space than in the spring. The emergence of aquatic perennials in shallow stands with a soft swamp substrate is characteristic. On the basis of the inventories made, a spatial matrix of existing plants was made which, at the stage of hydrodynamic model calibration, constituted the basis for spatial MRCn in the riverbed. 


\subsection{Hydrodynamic model}

For hydrodynamic modelling, the Nays2DH model implemented in the IRIC environment was used (https://i-ric.org). Nays $2 \mathrm{DH}$ is a computational model for simulating unsteady horizontal two-dimensional (2D) flow, sediment transport, and morphological changes of bed and banks in rivers which was developed by Shimizu et al. $[17,18]$.

The two-dimensional model is based on the GRID mesh characterizing the dimensions of the analysed section of the channel (11 m wide and $47 \mathrm{~m}$ in length) and spatial resolution for the calculation of $0.2 \mathrm{~m} \times 0.2 \mathrm{~m}$. The GRID mesh prepared in this way has been applied to the bed bathymetry on the basis of field values additionally interpolated to GRID mesh in the ArcGIS environment using the Natural Neighbour method and a pre-prepared MRCn distribution interpolated using the Kriging method also in the ArcGIS environment. The calculations were made for the steady flow conditions for the simulation time $T=660 \mathrm{~s}$ with the time step $\Delta t=0.02 \mathrm{~s}$. As the upper boundary condition, a constant inflow was established with the intensity specified in a given scenario, while free outflow was established as the bottom boundary condition. In the model for the purposes of this study, the calculation of the bed deformation was excluded, which allows to assess additional morphological changes.

The calibration was carried out, according to the diagram in Fig. 6, for both scenarios separately due to different bathymetry and different flows measured during field tests. The elevation of surface and the velocities measured in the field were checked. The calibration consisted in such selection of the factor of roughness $(N)$ that after multiplication by Plants matrix $\left(P_{i, j}\right)$, the MRCn matrix $\left(n_{i, j}\right)$ was obtained, which after entering the model will give the results of the velocity and elevation of surface water similar, as much as possible, to field measurements.

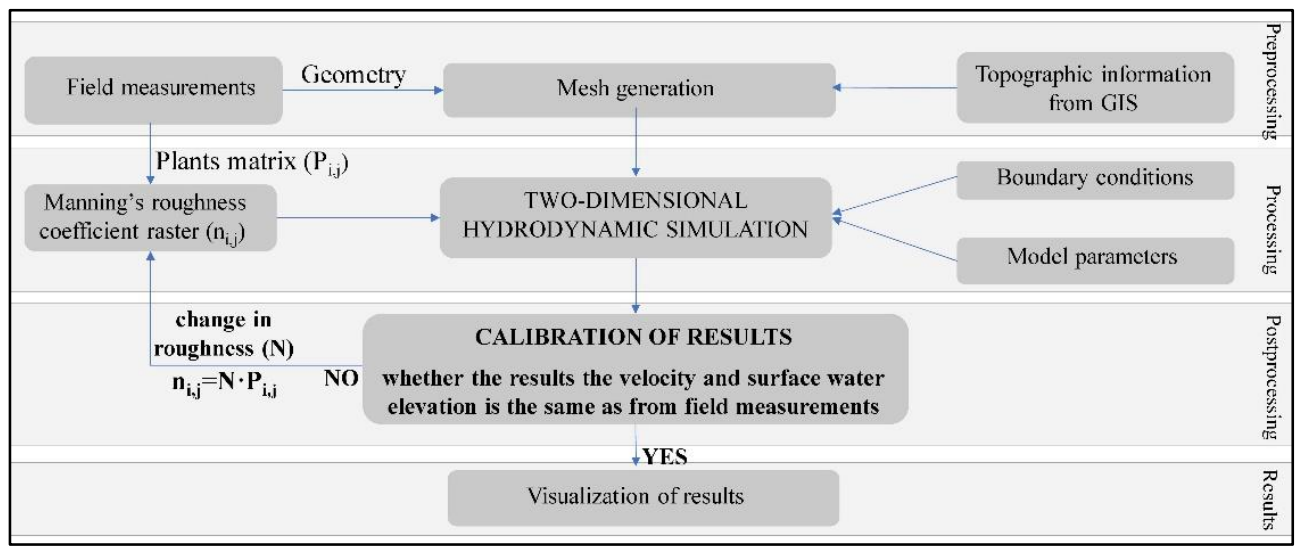

Fig. 6. Calibration diagram used in the test. 


\section{Results}

As part of the performed calibrations, the MRCn matrix was obtained (n) for both scenarios, which are presented in Fig. 7. The much smaller $n$ values for Scenario 1 (April) than for Scenario 2 (October) are noticeable. The value of the coefficient calculated for the whole section for the scenario 1 are: $n_{\text {mean }}=0.039 \mathrm{~ms}^{-1 / 3}, n_{\max }=0.069 \mathrm{~ms}^{-1 / 3}$, and for the scenario 2 : $n_{\text {mean }}=0.055 \mathrm{~ms}^{-1 / 3}, n_{\max }=0.088 \mathrm{~ms}^{-1 / 3}$.

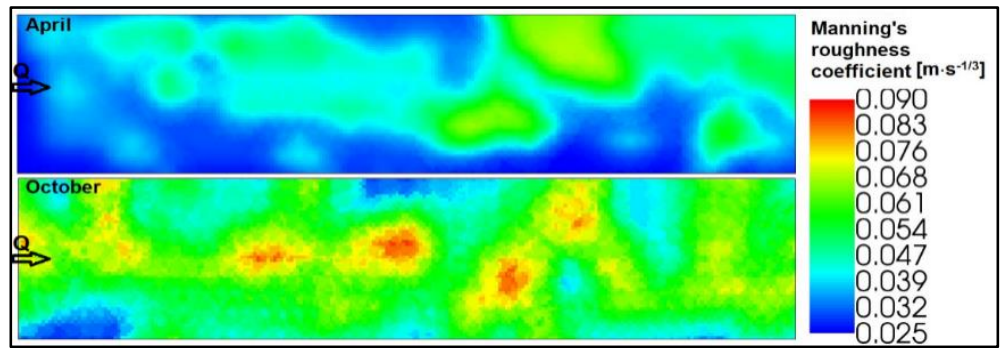

Fig. 7. Calibrated distribution of the MRCn in April (scenario 1) and in October (scenario 2).

Selected results of the simulations carried out for 6 different flows are presented in table 2. The obtained results point to the significant impact of plants primarily on the elevation of surface in autumn conditions compared to spring ones. Differences are $H=0.10-0.13 \mathrm{~m}$ and decrease with increasing flow rates (Fig. 8A). Analysis of the whole riverbed in terms of velocity did not show significant differences in the maximum velocity in the bed nor the mean velocity. The mean velocity differences are $u_{\text {mean }}=-0.002-0.009 \mathrm{~ms}^{-1}$ and increase very slightly with the flow rate (Fig. 8B), while the maximum velocity $u_{\max }=-0.0094--0.013 \mathrm{~ms}^{-1}$ and decrease with the flow rate (Fig. $8 \mathrm{C}$ ). The table also show analysis results for the maximum total shear stress, showing that the difference between scenario 1 and scenario 2 one is $S=-1.6-3.4 \mathrm{Nm}^{-2}$ and increases with the flow rate (Fig. 8D).

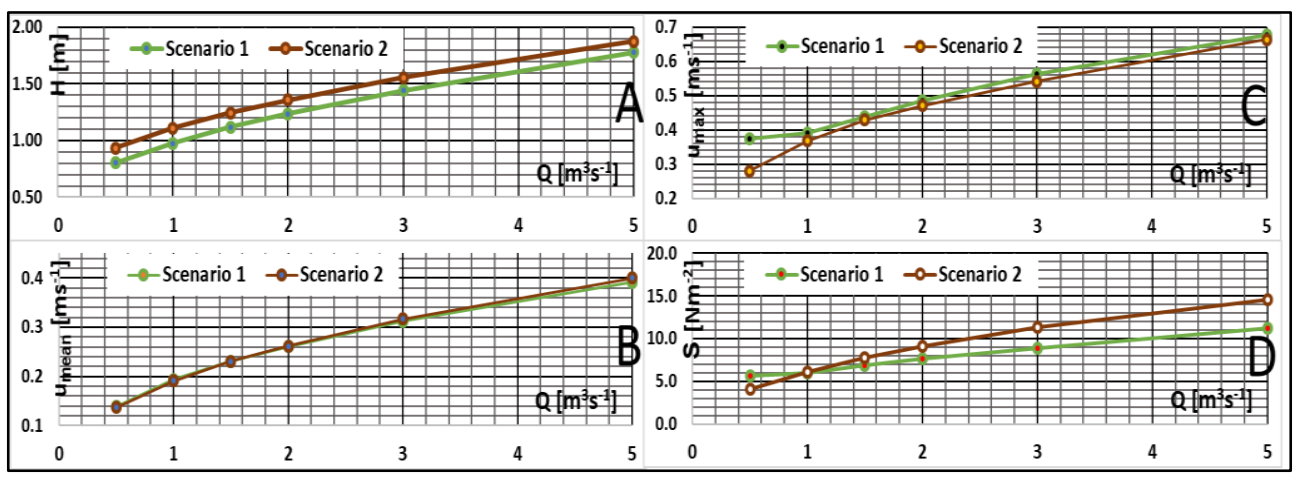

Fig. 8. Graph of the flow rate and: A. average surface of elevation $(\mathrm{H}), \mathrm{B}$. mean flow velocity $\left(u_{\text {mean }}\right)$, C. Maximum flow velocity $\left(u_{\max }\right)$, D. shear stress $(\mathrm{S})$. 
Table 2. Selected results of simulations carried out for 6 flows $\left(Q-\right.$ flow $\left[\mathrm{m}^{3} \mathrm{~s}^{-1}\right], u_{m e a n}-$ mean velocity $\left[\mathrm{ms}^{-1}\right], u_{\max }-$ maximal velocity $\left[\mathrm{ms}^{-1}\right], S$ - shear stress $\left[\mathrm{Nm}^{-2}\right], \Delta$-differences between scenarios 1 and 2).

\begin{tabular}{|c|c|c|c|c|c|c|c|c|c|c|c|c|c|c|}
\hline & \multicolumn{2}{|c|}{$Q$} & \multicolumn{3}{|c|}{$\boldsymbol{H}$} & \multicolumn{3}{|c|}{$u_{m e a n}$} & \multicolumn{3}{|c|}{$u_{\max }$} & \multicolumn{3}{|c|}{$S$} \\
\hline & 1 & 2 & 1 & 2 & $\Delta$ & 1 & 2 & $\Delta$ & 1 & 2 & $\Delta$ & 1 & 2 & $\Delta$ \\
\hline $\mathrm{Qk}$ & 1.12 & 0.65 & 1.01 & 1.00 & - & 0.204 & 0.156 & - & 0.396 & 0.314 & - & 6.3 & 4.7 & - \\
\hline Q1 & 0.5 & 0.5 & 0.80 & 0.94 & 0.13 & 0.139 & 0.137 & -0.002 & 0.374 & 0.28 & -0.094 & 5.7 & 4.1 & -1.6 \\
\hline Q2 & 1 & 1 & 0.98 & 1.11 & 0.13 & 0.194 & 0.191 & -0.003 & 0.392 & 0.368 & -0.024 & 6.0 & 6.1 & 0.1 \\
\hline Q3 & 1.5 & 1.5 & 1.12 & 1.24 & 0.13 & 0.231 & 0.231 & 0 & 0.438 & 0.429 & -0.009 & 6.9 & 7.8 & 0.8 \\
\hline Q4 & 2 & 2 & 1.24 & 1.36 & 0.12 & 0.261 & 0.262 & 0.001 & 0.486 & 0.471 & -0.015 & 7.7 & 9.1 & 1.5 \\
\hline Q5 & 3 & 3 & 1.44 & 1.56 & 0.11 & 0.312 & 0.317 & 0.005 & 0.562 & 0.542 & -0.02 & 8.9 & 11.3 & 2.4 \\
\hline Q6 & 5 & 5 & 1.78 & 1.88 & 0.10 & 0.391 & 0.4 & 0.009 & 0.677 & 0.664 & -0.013 & 11.2 & 14.6 & 3.4 \\
\hline
\end{tabular}
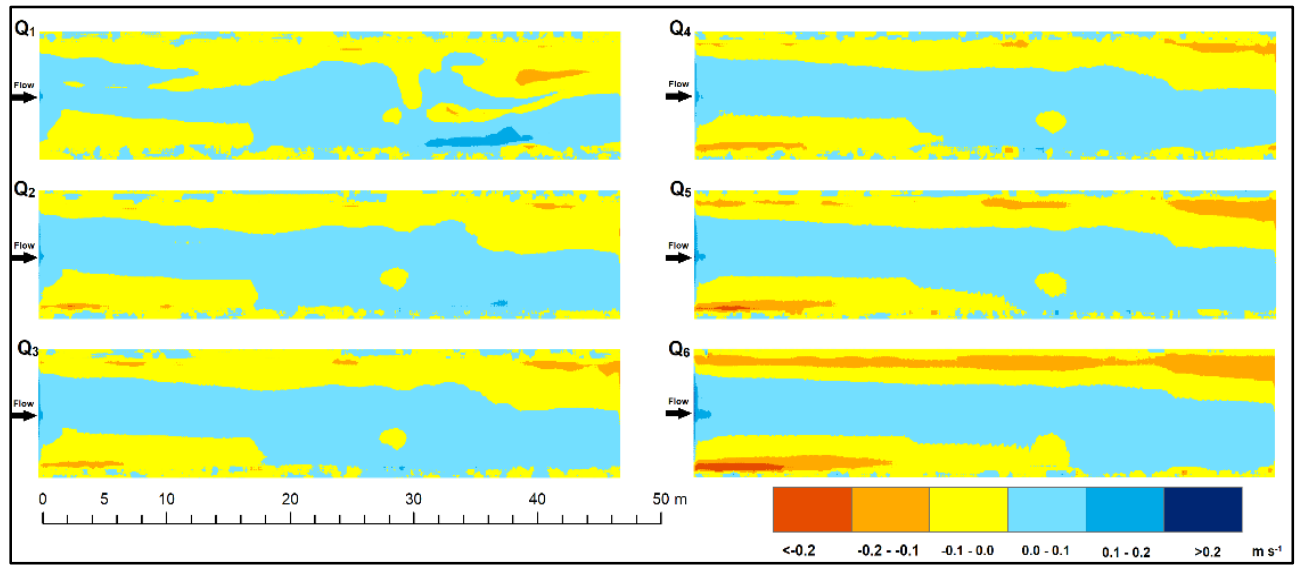

Fig. 9. Distribution of velocity variation between scenario 1 and scenario 2 for different flow rates.

The shown changes between scenario 1 and 2 in medium and maximum velocities in terms of the whole riverbed constituted very small values, therefore spatial velocity changes were also examined. It was done by calculating the differences in each computational cell of the hydrodynamic model. The differences between individual flows are from $-0.35 \mathrm{~ms}^{-1}$ to $0.27 \mathrm{~ms}^{-1}$ and increase with the flow rate (Fig. 9).Positive velocity differences (spring flows higher than in autumn) occur in the central part of the riverbed, while the opposite tendency occurs at the banks.

\section{Conclusions}

The analyses carried out have unequivocally confirmed the impact of plants on seasonal changes in hydraulic conditions in the overgrown lowland river bed. It has been shown that the development of plants affects the increase of the MRCn in the channel and the change in spatial velocity distribution, despite the persistence of similar values of medium and maximum velocity. It has also been proved that the presence of plants affects the accumulation of water, which decreases with increasing flow rate. In addition, the differences in shear stress between spring and autumn conditions have been shown to increase with the flow rate. The examined plant impact is important for hydraulic changes at low and medium flows, which in the studied conditions of the Ślęza River occur for the longest time during the year. The established hydraulic changes are followed by the morphological changes in the riverbed, which may be the subject of further work. 
The study was performed with Nays2DH and IRIC software both on free license. The data were provided by the Institute of Meteorology and Water Management - National Research Institute.

\section{References}

1. E. J. Hickin, Can.Geogr. 28 (1984)

2. R. C. Grabowski, A. M. Gurnell, River Rec. Applic. 32 (2016)

3. A. M. Gurnell, Earth Surf. Process. Landforms, 40 (2015)

4. A. M. Łoboda, R. J. Bialik, M. Karpiński, Ł. Przyborowski, Aquat. Bot. 147 (2018)

5. A. M. Łoboda, R. J. Bialik, M. Karpiński, Ł. Przyborowski, Polish J. Environ. Stud. 28 (2019)

6. F. M. Bakry, T. K. Gates, A. F. Khattab, J. Irrig. Drain. Eng. 118 (1992)

7. T. Helmiö, J. Järvelä, Boreal Environ. Res. 9 (2004)

8. L. De Doncker, P. Troch, R. Verhoeven, K. Bal, P. Meire, J. Quintelier, Environ. Fluid Mech. 9 (2009)

9. P. D. Champion, C. C. Tanner, Hydrobiologia, 441 (2000)

10. M. T. O’Hare, C. McGahey, N. Bissett, C. Cailes, P. Henville, P. Scarlett,. J. Hydrol. 385 (2010)

11. S. Song, B. Schmalz, Y. P. Xu, N. Fohrer, Water Resour. Manag. 31 (2017)

12. P. Marcinkowski, A. Kiczko, T. Okruszko, Water, 10 (2018)

13. N. Walczak, M. Hammerling, M. Spychała, J. Nieć, J. Ecol. Eng. 16, 5 (2015)

14. V.T. Chow, Open-Channel Hydraulics (1959)

15. T. Kałuża, A. Radecki-Pawlik, K. Szoszkiewicz, K. Plesiński, B. Radecki-Pawlik, I. Laks, Sci. Total Environ. 627 (2018)

16. P. M. Rowiński, K. Västilä, J. Aberle, J. Järvelä, M. B. Kalinowska, J. Ecohydrology and Hydrobiology, 18 (2018)

17. C. L. Jang, Y. Schimizu, J. Hydraul. Eng. 131, 7 (2005)

18. Y. Shimizu, H. Takebayashi, T. Innoue, M. Hamaki, T. Iwasaki, M. Nabi, IRIC Software. Changing River Science. Nays2DH Solver Manual (2011) 